\title{
The association between aspects of carer distress and time until nursing home admission in persons with Alzheimer's disease and dementia with Lewy bodies
}

\author{
Toril Marie Terum, ${ }^{1,2,3,4}$ Ingelin Testad, ${ }^{2,5,6}$ Arvid Rongve, 3,7 Dag Aarsland, 2,6 \\ Ellen Svendsboe, ${ }^{8}$ and John Roger Andersen ${ }^{1,4}$ \\ ${ }^{1}$ Faculty of Health and Caring Sciences, Western Norway University of Applied Sciences, Førde, Norway \\ ${ }^{2}$ Centre for Age-related Medicine (SESAM), Stavanger University Hospital, Stavanger, Norway \\ ${ }^{3}$ Department of Clinical Medicine (K1), University of Bergen, Bergen, Norway \\ ${ }^{4}$ Center of Health Research, Førde Hospital Trust, Førde, Norway \\ ${ }^{5}$ University of Exeter Medical School, St Luke's Campus, University of Exeter, Exeter, UK \\ ${ }^{6}$ Department of Old Age Psychiatry, Institute of Psychiatry, Psychology E Neuroscience, King's College London, London, UK \\ ${ }^{7}$ Department of Research and Innovation, Helse Fonna, Haugesund, Norway \\ ${ }^{8}$ Faculty of Health and Caring Sciences, Western Norway University of Applied Sciences, Stord, Norway
}

Abstract

Objective: The aim of this study was to explore the association between specific aspects of carer distress and time until nursing home admission (NHA) in people with mild dementia.

Design: Prospective cohort study.

Setting: Participants were recruited from the Dementia Study of Western Norway (DemVest).

Participants: This study included 107 participants admitted to a nursing home who were diagnosed with Alzheimer's disease (AD, $n=64$ ) and dementia with Lewy bodies (DLB, $n=43$ ) and their primary carers.

Measurements: The Relative Stress Scale (RSS) was used to assess the level of reported distress in carers. Adjusted partial least square (PLS) prediction analysis of baseline items of the RSS was used to study the associations between individual items of the RSS and time until NHA.

Results: Carer distress is an important contributor to early NHA, explaining $19.3 \%$ of the total variance of time until NHA in the model without covariates. In the adjusted PLS model, the most important RSS predictors of time until NHA were feeling frustrated (estimate $=-137$; CI, $-209,-64.5$ ), having limitations on social life (estimate $=-118$; CI, $-172,-64$ ), not being able to get away on vacation (estimate -116 ; CI, -158.3 , -73.7 ), and feeling unable to cope with the situation (estimate $=-63$; CI, $-122.6,-3.4$ ).

Conclusions: Preservation of the informal care capacity represents important steps for improving the management of resources in dementia care. This study identifies aspects of carer distress associated with a shorter time until NHA. Looking beyond the sum score of the RSS helps promote the development of flexible and tailored interventions and perhaps delay NHA.

Key words: dementia, Alzheimer's disease, dementia with Lewy bodies, carers, nursing homes

\section{Introduction}

Dementia has been identified as one of the most important contributors to disability, dependency, and transitioning into nursing home care in the elderly (Prince et al., 2013). Fifty million people

Correspondence should be addressed to: Toril Marie Terum, Western Norway University of Applied Sciences, Campus Førde, Postboks 523, 6803 Førde, Norway. Phone: + 996105 34. Email: toril.marie.terum@hvl.no. Received 07 Jan 2020; revision requested 11 Feb 2020; revised version received 06 Mar 2020; accepted 09 Mar 2020. First published online 11 Jun 2020 are currently living with dementia worldwide, and the total estimated global cost of dementia in 2018 was US $\$ 1$ trillion (Patterson, 2018). As the world's population ages, the prevalence of dementia is expected to increase, placing significant burdens on informal carers, the care system, and the economy (Livingston et al., 2017; Prince, 2015; Wimo et al., 2013).

Currently, about half of people with dementia in high-income countries are cared for in nursing homes (Prince et al., 2013). The potential negative 
effects of institutionalization on the quality of life for people with dementia, future shortage of nursing home beds, and high direct costs associated with nursing home care make delaying the transition into nursing homes a priority in high-income countries (Prince et al., 2013). The circumstances under which people with dementia are admitted to nursing home are multifactorial and often the result of complex interactions among characteristics of people with dementia, informal carers, and the care system (Cepoiu-Martin et al., 2016).

A substantial number of empirical studies considering factors associated with nursing home admission (NHA) in people with dementia have been summarized in four systematic reviews. All four identify carer burden and distress as a consistent and significant predictor of NHA (Cepoiu-Martin et al., 2016; Gaugler et al., 2009; Luppa et al., 2008; Toot et al., 2017). Less is known about the effect of aspects of carer burden and distress on NHA.

One aspect of carer burden and distress found to predict NHA is increased role captivity, in terms of feeling trapped in care responsibilities (Gaugler et al., 2000). The finding replicates an earlier report by Aneshensel and colleagues (1995). Role overload, in terms of feeling overwhelmed and worn out by caregiving responsibilities, and worry/strain, was according to Gaugler et al. (2000) not found to predict NHA. However, the protective effect of being married and living with a family carer is documented in multiple studies (Cepoiu-Martin et al., 2016; Luppa et al., 2008). Consistent and significant care-recipient predictors of NHA include severity of cognitive impairment, activities of daily living (ADL) deficiencies, and neuropsychiatric symptoms (NPSs) of dementia (Cepoiu-Martin et al., 2016; Gaugler et al., 2009; Luppa et al., 2008; Toot et al., 2017). The effect of community-based services is unclear with both high and low levels of service use leading to NHA according to Toot et al. (2017) and Luppa et al. (2008).

In most countries, resources available in the continuing care system are limited. A deeper understanding of the circumstances under which people with dementia require NHA represents important steps for improving the management of resources in dementia care. However, the burden placed on informal carers has to be taken into consideration. Carer distress is associated with impaired quality of life (Sörensen et al., 2006), decline in general health, and psychiatric morbidities (Svendsboe et al., 2016; Ulstein, 2007).

We have previously demonstrated that compared to people diagnosed with Alzheimer's disease (AD), people diagnosed with dementia with Lewy bodies (DLB) had nearly 2 years shorter time until NHA
(Rongve et al., 2014). In addition to a DLB diagnosis, Rongve and colleagues (2014) found that higher RSS, sum scores predicted faster admission to a nursing home. In this study, we want to further explore this association. To the best of our knowledge, no studies have explored the association between the aspects of carer burden and distress, identified through individual items of a burden or distress scale, and the time until NHA.

We think that looking beyond the sum score of the RSS helps promote the development of flexible and tailored interventions and that accommodating the needs of informal carers might delay NHA. Therefore, the aim of this study was to explore the association between specific aspects of carer distress, identified through individual items of the RSS, and time until NHA in people with mild dementia.

\section{Methods}

This study is part of the Dementia Study of Western Norway (DemVest). The DemVest study is a longitudinal dementia cohort study with annual assessments of people referred to dementia clinics in Western Norway between 2005 and 2008. After 2008, people diagnosed with DLB and Parkinson's disease dementia (PDD) were selectively recruited to enhance the number of participants in these diagnostic groups (Aarsland et al., 2008).

A first-time diagnosis of dementia was made, according to the Diagnostic and Statistical Manual for Mental Disorders, 4th edition (DSM-IV), and mild dementia defined as Mini Mental Status Examination (MMSE) score of at least 20 or a Clinical Dementia Rating-scale global score $=1$.

A diagnosis of $\mathrm{AD}$ was made according to the National Institute of Neurological and Communicative Disorders and the Stroke-Alzheimer's Disease and Related Disorders Association (Mckhann et al., 1984) and a diagnosis of DLB according to the revised Consensus Guidelines for the Clinical Diagnosis of Probable and Possible Dementia With Lewy Bodies (McKeith et al., 2005). A pathological diagnosis was available for 56 patients in the DemVest cohort, showing a diagnostic accuracy of more than 80\% (Skogseth et al., 2017).

\section{Eligibility criteria}

This study included people diagnosed with $\mathrm{AD}$ and DLB with a participating primary carer (spouse/ partner or adult child). All participants had mild dementia and were living at home at the time of inclusion and were later admitted to a nursing home. People diagnosed with AD and DLB and who are 
still living at home were excluded, along with patients with acute delirium or confusion, terminal illness, recently diagnosed with a major somatic illness, or previously diagnosed with bipolar disorder or psychotic disorder.

\section{Ethics}

The Regional Ethics Committee for Medical Research Ethics in Western Norway (DemVest REK 2010/633) and the Norwegian authorities for the collection of medical data approved the DemVest study. All participants, including people diagnosed with dementia and their primary carer, provided written consent.

\section{Dependent variable}

The time until NHA was measured as days from the date of inclusion and diagnosis until the date each participant was admitted to a nursing home.

\section{Independent variables}

Aspects of CARER Distress

Carer distress was assessed using the 15-item Norwegian Relative Stress Scale (RSS), which was translated and adapted to Norwegian language and culture with a Chronbach's $\alpha$ of 0.91 (Ulstein et al., 2007b).

The RSS is a self-administered questionnaire designed to assess various aspects of distress experienced by an informal carer providing care for a relative with dementia and include subjective emotional responses, restrictions in the carers' social lives, and negative feelings associated with the person and his or her behaviors (Greene et al., 1982). The questionnaire consists of 15 items, each scored at five levels of intensity (0-4), with higher scores indicating more severe stress. A score above 23 on the RSS according to Ulstein et al. (2007a) indicates an increased risk of clinically significant psychological distress for the caregiver.

\section{Covariates}

In addition to sociodemographic variables such as sex, age, family relation (spouse or adult children), and dementia diagnosis, the cognitive functioning level was assessed by means of the Mini-Mental Status Evaluation (MMSE). The MMSE is a 30-point questionnaire that is used in both clinical and research settings to estimate the severity and progression of cognitive impairment (Folstein et al., 1975).

NPSs were assessed using the validated Norwegian version of the Neuropsychiatric Inventory (NPI) (Selbaek et al., 2008). The NPI is a widely used carerbased assessment scale developed to assess the psychopathology in people with dementia. The NPI rates each of the 12 NPSs on a frequency scale (0-4) and severity scale (0-3), with a higher score indicating more severe symptoms (Cummings, 1997).
The limitations in terms of daily activities were assessed using the Rapid Disability Rating Scale-2 (RDRS-2) and comprises items grouped into the following three domains: activities of daily living, degree of dependence, and cognitive impairment. All items are ranked on a scale (1-4), with higher scores indicating poorer function (Linn and Linn, 1982). Because RDRS-2 exists in both a 19-item version and a 21 -item version, z-scores were applied for this study.

Statistics

The characteristics of the entire sample $(n=107)$ are presented as proportions and mean values with standard deviations. Because of the highly nonnormal distribution of the individual RSS item scores, these were recoded into binary variables by comparing scores less than or equal to $1(\leq)$ versus scores greater than or equal to $2(\geq)$ in all analyses. First, mean values (days) with standard deviations until NHA are presented for participants scoring low $(\leq 1)$ and high $(\geq 2)$ on each individual RSS item. The independent t-test was applied to display the mean difference in time with $95 \%$ confidence intervals (CIs) until NHA between the two groups. Second, partial least square (PLS) regression models were used to study the associations between time until NHA and baseline items of the RSS. PLS regression allows for multivariate modeling in samples with many variables related to observations. We first ran a model by including only the 15 individual RSS items. Then, we made adjustments of diagnosis (AD versus $\mathrm{DLB}$ ), sex (female versus male), age (years), number of children ( $\leq 1$ versus $\geq 2$ ), social status (in a relationship [married or partner] versus divorced/widow[er]), family relation (spouse versus child), MMSE total score, RDRS-2, z-score, duration of symptoms prior to diagnosis (years), and NPI total intensity. All continuous covariates were standardized to binary variables using a median split before being entered into the PLS model. To test the robustness of the findings, models were crossvalidated, excluding every fourth subject. We report estimates of days living at home until NHA with CIs and the explained variance (R2) of the PLS models (model with only RSS items versus full model). All CIs not including the value of zero were considered statistically significant. The PLS analysis was performed using Sirius vs. 11.0 (Pattern Recognition Systems, Bergen, Norway), while other analyses were conducted using SPSS version 24 .

\section{Results}

A total of 223 people diagnosed with mild dementia were recruited in the DemVest study. This study 
Table 1. Descriptive analysis of patient and carer variables

\begin{tabular}{|c|c|}
\hline & $N=107$ \\
\hline Spouse/adult child & $50 / 57$ \\
\hline $\mathrm{AD} / \mathrm{DLB}$ & $64 / 43$ \\
\hline Sex (female/male) & $66 / 41$ \\
\hline Age (years), mean (SD) & $75.9( \pm 7.4)$ \\
\hline $\begin{array}{l}\text { Social status (married or partner/divorced/ } \\
\text { widow(er) }\end{array}$ & $62 / 4 / 40$ \\
\hline Number of children (one child/ $\geq 2$ ) & $72 / 29$ \\
\hline MMSE total, mean (SD) & $23.7( \pm 2.9)$ \\
\hline RDRS-2, z-scores mean (SD) & $-0.32( \pm 1.07)$ \\
\hline $\begin{array}{l}\text { Duration of symptoms prior to inclusion } \\
\text { mean (SD) }\end{array}$ & $2.9( \pm 2.3)$ \\
\hline NPI, total intensity mean (SD) & $19.5( \pm 18.7)$ \\
\hline RSS, total mean (SD) & $17.7( \pm 11.5)$ \\
\hline
\end{tabular}

Abbreviation: Mean; SD, standard deviation; NPI, Neuropsychiatric Inventory; MMSE, Mini-Mental State Examination; RDRS-2, Rapid Disability Rating Scale-2; RSS, Relative Stress Scale.

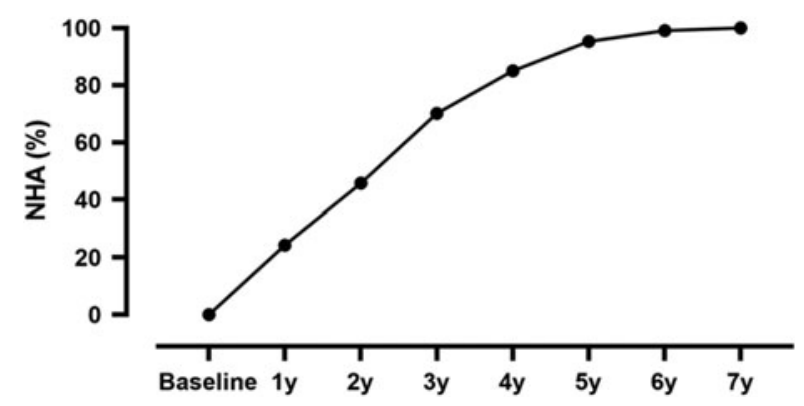

Figure 1. Illustration of the proportion (\%) of patients admitted to a nursing home.

included 107 participants admitted to nursing home and their primary carer. Sixty-four persons were diagnosed with $\mathrm{AD}$ and 43 were diagnosed with DLB. The majority of patients were women $(61.7 \%)$, with a mean age of $75.9(\mathrm{SD}, 7.4)$ and a mean MMSE score of 23.7 (SD, 2.9). All participants were living at home at the time of inclusion. Of the primary carers, $53.3 \%$ were adult children and $46.7 \%$ spouses/partners. For more details, see Table 1. Twenty-four percent of all participants $(n=107)$ were admitted to nursing home during the first year, and after 3 years, $70 \%$ were cared for in care homes, see Figure 1. The last participant to be admitted to a nursing home was admitted in June 2012. At that time, 17 people diagnosed with AD and 12 people diagnosed with DLB $(n=29)$, with a primary carer, had died at home before NHA. The remaining participants $(n=47)$ were living at home at this time.

An independent-samples t-test was conducted to compare time living at home before NHA in participants scoring high $(\geq 2)$ and low $(\leq 1)$ on individual RSS items. Except for three RSS items, all group means were significantly different. The items with the highest mean difference were item 8 (How much has your social life been affected? $($ mean $=455$, CI 253,656)), item 7 (Do you find it difficult to get away on holiday? ( mean $=454$, CI 257, 652)), item 1 (Do you ever feel you can no longer cope with the situation? (mean $=410$, CI 193, 627)), and item 15 (Do you ever feel frustrated at times with ...? (mean $=407$, CI 205, 609)). These findings indicate that carers scoring high on specific RSS items are admitted to nursing home sooner. For more details, see Table 2 .

In the unadjusted PLS analysis, which determined only the effect of individual items of the RSS on time until NHA, the explained variance was $19.3 \%$. The explained variance in the full PLS model, including the covariates, was $43 \%$. Of the individual RSS items, the adjusted PLS model showed a high score on item 15 (Do you ever feel frustrated at times with the person you're caring for? (estimate $=137, \mathrm{CI}-209.5,-64.5)$ ), item 8 (How much has your social life been (estimate $=-118$, CI $-172,6.4$ )), item 7 (Do you find it difficult to get away on holiday? (estimate $=-116$, CI $-158.3,-73.7)$ ), and item 1 (Do you ever feel you can no longer cope with the situation? (estimate $=-63$, CI $-122.6,-3.4)$ ). For more details, see Table 3 and Figure 2.

Furthermore, the PLS model showed that covariates associated with shorter time until NHA include a diagnosis of DLB (estimate $=-157.0$; CI, $-228.6,-85.4)$ and the carer being a child (estimate $=-218$; CI, $-278.1,-157.9$ ) and the person with dementia being divorced/widowed (estimate - 199; CI, 267.5, - 130.5), having a higher education (estimate $=92.5$; CI, 9.1, 175.9), having a higher MMSE score (estimate $=127.0$ (CI, 53.3, 200.7), having a higher RDRS-2, z-score (estimate $=-100.3$; CI, $-143.0,-63.0$ ), having a longer duration of symptoms prior to diagnosis (estimate $=74.2$; CI, 1.5, 146.9), and having a higher total intensity score (frequency $\times$ intensity) on the NPI (estimate $=-65$; CI, $-127.1,-2.9$ ). Male sex, age, and number of children did not predict NHA (data not shown).

\section{Discussion}

Findings of this study indicate that feeling frustration with the person one is caring for, feeling that the care responsibilities prevent one's from being social outside of the home and getting away on holiday, and an overall feeling of not coping with the situation are important predictors of shorter time until NHA. In addition to identifying individual items of the RSS 
Table 2. Mean difference in time living at home before NHA using an independent t-test to compare participants scoring low $(\leq 1)$ and high $(\geq 2)$ on the individual RSS items

\begin{tabular}{|c|c|c|c|c|c|}
\hline \multirow[t]{2}{*}{ RSS, ITEMS } & \multicolumn{2}{|r|}{$\leq 1$} & \multicolumn{2}{|r|}{$\geq 2$} & \multirow[b]{2}{*}{ Mean difference $(\mathrm{CI})$} \\
\hline & $\%$ & Mean, SD & $\%$ & Mean, SD & \\
\hline 1. Do you ever feel you can no longer cope with the situation? & 67 & $1012 \pm 524$ & 33 & $602 \pm 471$ & $410(193,627)$ \\
\hline 2. Do you ever feel you need a break? & 51 & $1061 \pm 468$ & 49 & $684 \pm 560$ & $376(168,585)$ \\
\hline 3. Do you ever get depressed with the situation? & 51 & $971 \pm 513$ & 49 & $782 \pm 557$ & $188(-27,403)$ \\
\hline 4. Has your own health suffered at all? & 69 & $968 \pm 523$ & 31 & $675 \pm 532$ & $294(65,523)$ \\
\hline 5. Do you worry about accidents happening to ...? & 44 & $1022 \pm 505$ & 56 & $777 \pm 545$ & $245(31,459)$ \\
\hline 6. Do you ever feel that there will be no end to the problem? & 66 & $973 \pm 541$ & 34 & $692 \pm 497$ & $282(58,505)$ \\
\hline 7. Do you find it difficult to get away on holiday? & 51 & $1101 \pm 509$ & 49 & $647 \pm 475$ & $454(257,652)$ \\
\hline 8. How much has your social life been affected? & 56 & $1080 \pm 536$ & 44 & $625 \pm 442$ & $455(253,656)$ \\
\hline 9. How much has the household routine been upset? & 68 & $946 \pm 564$ & 32 & $728 \pm 470$ & $218(-14,450)$ \\
\hline 10. Is your sleep interrupted by $\ldots$ ? & 72 & $951 \pm 526$ & 28 & $683 \pm 559$ & $268(26,509)$ \\
\hline 11. Has your standard of living been reduced? & 65 & $978 \pm 535$ & 35 & $694 \pm 517$ & $285(61,508)$ \\
\hline 12. Do you ever feel embarrassed by ...? & 87 & $907 \pm 564$ & 13 & $694 \pm 311$ & $213(-5,430)$ \\
\hline 13. Are you at all prevented from having visitors? & 87 & $921 \pm 534$ & 13 & $602 \pm 522$ & $319(5,634)$ \\
\hline 14. Do you ever get cross or angry with ...? & 64 & $967 \pm 553$ & 36 & $719 \pm 486$ & $248(26,470)$ \\
\hline 15. Do you ever feel frustrated at times with ...? & 52 & $1074 \pm 523$ & 48 & $667 \pm 481$ & $407(205,609)$ \\
\hline
\end{tabular}

Abbreviation: Mean; SD, standard deviation; mean difference; CI, confidence interval.

Table 3. Partial least square regression prediction analysis of baseline items of the Relative Stress Scale on time (days) living at home before nursing home admission

\begin{tabular}{|c|c|c|}
\hline RSS ITEMS & MEAN DAYS & CI \\
\hline 1. Do you ever feel you can no longer cope with the situation? & -63.0 & $-122.6,-3.4$ \\
\hline 2. Do you ever feel that you need a break? & -45.7 & $-101.6,10.2$ \\
\hline 3. Do you ever get depressed by the situation? & 38.1 & $-24.3,100.5$ \\
\hline 4. Has your own health suffered at all? & 2.4 & $-53.9,58.7$ \\
\hline 5. Do you worry about accidents happening to the person you're caring for? & -10.0 & $-84.8,64.8$ \\
\hline 6. Do you ever feel that there will be no end to the problem? & -25.6 & $-78,5,27.3$ \\
\hline 7. Do you find it difficult to get away on holiday/vacation? & -116.0 & $-158.3,-73.7$ \\
\hline 8. How much has your social life been affected? & -118.0 & $-172.0,-64.0$ \\
\hline 9. How much has the household routine been upset? & -2.8 & $-63.1,57.6$ \\
\hline 10. Is your sleep interrupted by the person you're caring for? & -11.2 & $-72.7,50.3$ \\
\hline 11. Has your standard of living been reduced? & 5.7 & $-49.8,61.2$ \\
\hline 12. Do you ever feel embarrassed by the person you're caring for? & 6.3 & $-22.1,34.7$ \\
\hline 13. Are you at all prevented from having visitors? & -18.8 & $-74.1,36.5$ \\
\hline 14. Do you ever get cross or angry with the person you're caring for? & -49.2 & $-113.9,15.5$ \\
\hline 15. Do you ever feel frustrated at times with the person you're caring for? & -137.0 & $-209.5,-64.5$ \\
\hline
\end{tabular}

The most important items are shown in bold. The model is adjusted for patient sex, patient age and family relation to carer (spouse or adult children), patient marital status, number of children, patient diagnosis of Alzheimer's disease or dementia with Lewy bodies, MMSE (Mini Mental Status Evaluation), duration of symptoms prior to diagnosis, NPI sum score, and RDRS-2 z-score.

Abbreviation: CI, confidence interval.

associated with time until NHA, this study suggests that the mechanism behind this is multifactorial.

Although overall carer burden and distress are shown to predict time until NHA (Cepoiu-Martin et al., 2016; Gaugler et al., 2009; Luppa et al., 2008; Toot et al., 2017), no studies have explored the predictive value of specific aspects of carer distress identified through factor analysis or individual items on a burden or distress scale on time until NHA. However, based on relevant findings (Gaugler et al.,
2000; Adams, 2006; Baek, 2004) and Lazarus and Folkman (1984) theory of stress and coping, we seek to shed some light on the possible mechanism behind our findings.

Feeling frustrated at times with the person one is caring for is likely related to the fact that carers of people with dementia have a broad range of emotions related to their caregiving experiences, many of which are negative. Negative feelings, according to Adams (2006), include feelings of impatience, 


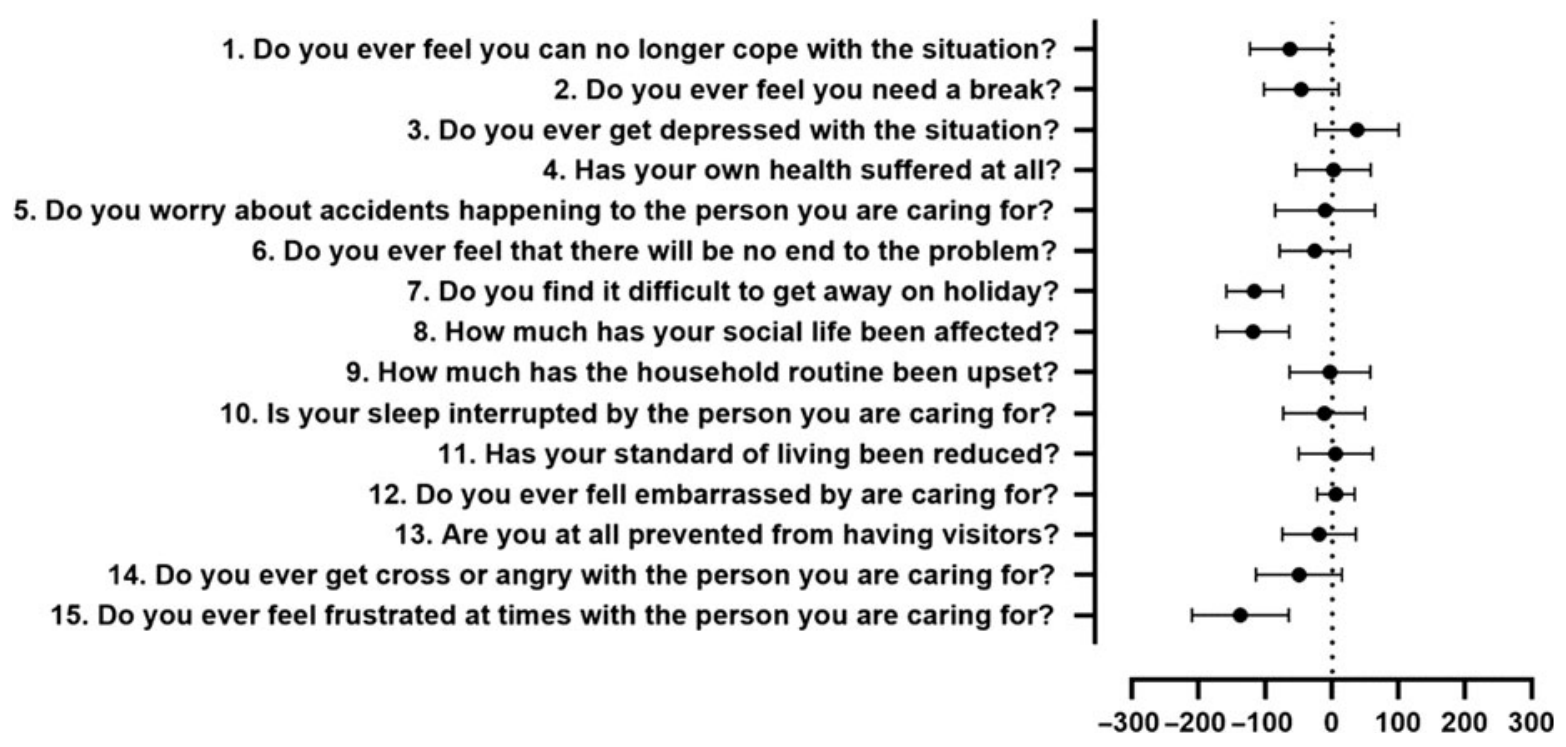

Figure 2. Illustration of findings of a partial least square regression prediction analysis of baseline items of the Relative Stress Scale on time (days) until nursing home admission.

frustration, resentment, and disappointment toward the person with dementia (Adams, 2006). However, the handling and channeling of negative feelings differ and adds to the burden of care of informal carers. Some carers report hiding their frustration, while others report feelings of guilt and shame because they take their frustration out on the person with dementia. Recognizing and normalizing the occurrence of these feelings are therefore of great importance. The fact that feeling frustrated at times with the person one is caring for was associated with a shorter time until NHA, as opposed to getting upset with or being embarrassed by the person with dementia, further highlights the importance of distinguishing between negative emotions and the effects of these emotions.

The findings of this study further reveal that feeling trapped and tied up, in terms of feeling one's social life has been affected and not being free to take a holiday, are aspects of carer distress predicting shorter time until NHA. These findings indicate that carers need to be able to take a break and have a social life outside of the house, free from care responsibilities, and thus we emphasize the importance of providing respite for informal carers. These findings correspond with findings in a study by Gaugler and colleagues (2000). They replicated an earlier report by Aneshensel and colleagues (1995) and found that role captivity was significant in precipitating NHA. Role captivity was in that study assessed using a 3-item scale focusing on the involuntary aspects of caregiving, referring to carers' feelings of being trapped and having no choice in their role. Role overload, or the extent to which carers feel overwhelmed and worn out by caregiving responsibilities, was not significant (Gaugler et al., 2000). According to Baek (2004), measuring how often carers feel trapped by their relatives' illness, want to run away, and want to be free to lead a life of their own, role captivity denoted how much carers want to give up their caregiving role.

The last RSS item to stand out as a significant predictor of shorter time until NHA was feeling that you no longer can cope with the situation and is associated with a shorter time until NHA. This might indicate that carers have reached a point where they feel they no longer can handle the care responsibilities and want to give up the caregiving role. According to Lazarus and Folkman (1984), stress occurs when carers through appraisal see available resources and/or coping strategies to be inadequate (Lazarus and Folkman, 1984). Coping refers to a person's efforts to manage demands and determines the effect of stressors on his or her wellbeing and possibly time until NHA. Giving informal carers the opportunity to influence decisions, and be involved in the planning of interventions, might further support informal carers' effort to handle everyday care demands.

Finally, the findings of this study suggest that there is a multifactorial influence on time until NHA among people diagnosed with dementia (CepoiuMartin et al., 2016) and that carer distress is an important predictor of shorter time until NHA (Luppa et al., 2008; Gaugler et al., 2009; CepoiuMartin et al., 2016; Toot et al., 2017). Based on the PLS model, being diagnosed with DLB and divorced/widowed and having a more severe cognitive decline and ADL impairments, longer duration 
of symptoms prior to diagnosis, NPS, higher education, and carer being a child as opposed to spouse are associated with shorter time until NHA. To a large degree, these findings also correspond to existing evidence. It is well established that carerecipient variables, often referred to as primary stressors, including poorer cognition, greater severity of dementia, NPS, and ADL impairments, are consistent predictors of NHA along with carer burden and distress (Cepoiu-Martin et al., 2016; Luppa et al., 2008; Gaugler et al., 2009; Toot et al., 2017; Dufournet et al., 2019). According to a study comparing time until NHA among people diagnosed with DLB and AD, a diagnosis of DLB was associated with a shorter time to NHA (Rongve et al., 2014). However, according to a review by CepoiuMartin and colleagues (2016), the type of dementia did not predict NHA.

The evidence is further inconclusive regarding the effect of predisposing variables on time until NHA. However, several studies have found that being divorced or widowed, living alone, and carer being a child are associated with admission to nursing home (Luppa et al., 2008; Cepoiu-Martin et al., 2016). In contrast to previous findings, older age was not associated with shorter time until NHA in this study (Cepoiu-Martin et al., 2016).

A range of interventions in dementia care aim to help informal carers handle the demands of caregiving, reduce stress, and delay NHA. The current evidence is, however, inconsistent. The findings of a meta-analysis conducted by Spijker and colleagues (2008) showed that no pharmacological interventions significantly decreased the odds of institutionalization and significantly increased the time to institutionalization and that a combination of involvement and choice seems to be the main intervention characteristics that distinguished effective support programs from ineffective ones. According to Selwood and colleagues (2007), teaching carers coping strategies, especially individual interventions, appeared to improve carers' psychological health.

Multicomponent interventions, according to Dickinson et al. (2017), appear to have considerable potential to improve the health of carers of people with dementia and lead to benefits in costs of dementia care. However, the caregiving experience, perceived stress, coping, and time until NHA are a result of multiple factors, and more research on the effect of interventions and respite care on the burden of care and the carers' ability to stay in the caregiving role is needed.

\section{Strengths and weaknesses of the study}

The participants in the DemVest study were selected from a large, clinically defined cohort with rigorous diagnostic procedures, annual follow-up assessments, and low dropout. Sociodemographic data and data on the number of hours used on caregiving tasks on the carers were limited. This does not detract from our findings on the association between items of the RSS and time until NHA. It is, however, important to be aware that this might limit our understanding of why certain aspects of carer distress have a greater effect on time until NHA.

Furthermore, this study explores the association between specific aspects of carer distress and time until NHA in people with mild dementia using baseline data. Identifying aspects of carer distress that predict NHA is useful in planning early intervention. Furthermore, due to missing data on carer distress, baseline data were considered to be the most reliable. Exploring patterns of change could have further broadened our understanding of the circumstances under which people with dementia are admitted to nursing homes.

\section{Implications and suggestions for future research}

This study suggests that there is a multifactorial influence on time until NHA among people diagnosed with dementia and identifies aspects of carer distress associated with a shorter time until NHA.

Preservation of the informal care capacity represents important steps for improving the management of resources in dementia care. We think that looking beyond the sum score of the RSS promotes the development of flexible and tailored interventions. However, more research is needed in order to identify aspects of carer distress most strongly associated with NHA.

Based on the findings of this study, we argue that providing respite care is of great importance for informal carers, while at the same time pointing out the need to give informal carers the opportunity to influence decisions and be involved in the planning of interventions. This issue should be studied in future intervention studies.

\section{Conflict of interest}

None declared.

\section{Description of authors' roles}

Toril Marie Terum, John Roger Andersen, and Ingelin Testad designed this study, conducted the statistical analysis, and drafted the paper. Arvid Rongve, Ellen Svendsboe, and Dag Aarsland critically revised the paper for important intellectual content. All authors approved the final version for submission. The manuscript contains original 
unpublished work and is not submitted for publication elsewhere.

\section{Acknowledgments}

Thanks goes to our sponsors: The Research Council of Norway, grant number 213375; the Centre for Age-Related Medicine (SESAM), Stavanger University Hospital; Western Norway University of Applied Science, Førde; the Center of Health Research, Førde Hospital Trust; and the Centre for Development of Institutional and Home Care Services (USHT), Sogn og Fjordane. Furthermore, this paper represents independent research parly funded by the National Institute for Health Research (NIHR) Biomedical Research Centre at South London and Maudsley NHS Foundation Trust and King's College London. Last but not least, we sincerely thank all participating patients and their carers and the research staff in the DemWest study and Helse Vest.

\section{References}

Aarsland, D. et al. (2008). Frequency and case identification of dementia with Lewy bodies using the revised consensus criteria. Dementia and Geriatric Cognitive Disorders, 26, 445-452. doi: 10.1159/000165917

Adams, K. B. (2006). The transition to caregiving: the experience of family members embarking on the dementia caregiving career. Fournal of Gerontological Social Work, 47, 3-29. doi: 10.1300/J083v47n03_02

Aneshensel, C. S., Pearlin, L. I., Mullan, J. T., Zarit, S. H. and Whitlatch, C. J. (1995). Profiles in Caregiving: The Unexpected Career. San Diego: Academic Press.

Baek, J. (2004). Individual Variations in Family Caregiving Over the Caregiving Career. PhD Thesis. Pennsylvania: The Pennsylvania State University.

Cepoiu-Martin, M., Tam-Tham, H., Patten, S., Maxwell, C. J. and Hogan, D. B. (2016). Predictors of long-term care placement in persons with dementia: a systematic review and meta-analysis. International Fournal of Geriatric Psychiatry, 31, 1151-1171. doi: 10 $.1002 / \mathrm{gps} .4449$

Cummings, J.L. (1997). The Neuropsychiatric Inventory: assessing psychopathology in dementia patients. Neurology, 48, S10-S16. doi: 10.1212/WNL.48.5_Suppl_6.10S

Dickinson, C., Dow, J., Gibson, G., Hayes, L., Robalino, S. and Robinson, L. (2017). Psychosocial intervention for carers of people with dementia: what components are most effective and when? A systematic review of systematic reviews. International Psychogeriatrics, 29, 31-43. doi: 10 $.1017 /$ S1041610216001447

Dufournet, M. et al. (2019). Impact of cognitive, functional, behavioral disorders, and caregiver burden on the risk of nursing home placement. Fournal of the American Medical Directors Association, 20(10), s. 1254-1262. doi: 10.1016/j .jamda.2019.03.027
Folstein, M. F., Folstein, S. E. and Mchugh, P. R. (1975). Mini-mental state - practical method for grading cognitive state of patients for clinician. Fournal of Psychiatric Research, 12, 189-198.

Gaugler, J. E. et al. (2000). Predictors of institutionalization of cognitively impaired elders: family help and the timing of placement. The fournals of Gerontology Series B: Psychological Sciences and Social Sciences, 55, P247-P255. doi: 10.1093/geronb/55.4.P247

Gaugler, J. E., Yu, F., Krichbaum, K. and Wyman, J. F. (2009). Predictors of nursing home admission for persons with dementia. Medical Care, 47(2), 191-198. doi: 10 .1097/MLR.0b013e31818457ce

Greene, J., Smith, R., Gardiner, M. and Timbury, G. (1982). Measuring behavioural disturbance of elderly demented patients in the community and its effects on relatives: a factor analytic study. Age and Ageing, 11, 121-126. doi: 10.1093/ageing/11.2.121

Lazarus, R. S. and Folkman, S. (1984). Stress, Appraisal, and Coping. New York: Springer Publishing Company.

Linn, M. W. and Linn, B. S. (1982). The rapid disability rating-scale. 2. Fournal of the American Geriatrics Society, 30, 378-382. doi: 10.1111/j.1532-5415.1982.tb02835.x

Livingston, G. et al. (2017). Dementia prevention, intervention, and care. The Lancet, 390, 2673-2734. doi: 10 .1016/S0140-6736(17)31363-6

Luppa, M., Luck, T., Brahler, E., Konig, H. H. and Riedel-Heller, S. G. (2008). Prediction of institutionalisation in dementia. A systematic review. Dementia and Geriatric Cognitive Disorders, 26, 65-78. doi: 10 $.1159 / 000144027$

McKeith, I. G., Dickson, D. W., Lowe, J., et al. (2005) Diagnosis and management of dementia with Lewy bodies: third report of the DLB Consortium. Neurology, 65(12), 1863-1872. doi: 10.1212/01.wnl.0000187889.17253.b1

McKhann, G., Drachman, D., Folstein, M., Katzman, R., Price, D. and Stadlan, E. M. (1984). Clinical diagnosis of Alzheimer's disease: report of the NINCDS-ADRDA work group under the auspices of Department of Health and Human Services Task Force on Alzheimer's disease. Neurology, 34, 939-944. doi: 10.1212/wnl.34.7.939

Patterson, C. (2018). World Alzheimer report 2018: the state of the art of dementia research: new frontiers. Alzheimer's Disease International (ADI): London, UK.

Prince, M. J. (2015). World Alzheimer report 2015 - the global impact of dementia: an analysis of prevalence, incidence, cost and trends. Alzheimer's Disease International.

Prince, M. J., Prina, M. and Guerchet, M. (2013). World Alzheimer report 2013: journey of caring: an analysis of longterm care for dementia. Alzheimer's Disease International.

Rongve, A., Vossius, C., Nore, S., Testad, I. and Aarsland, D. (2014). Time until nursing home admission in people with mild dementia: comparison of dementia with Lewy bodies and Alzheimer's dementia. International Fournal of Geriatric Psychiatry, 29, 392-398. doi: 10.1002 /gps.4015

Selbaek, G., Kirkevold, O., Sommer, O. H. and Engedal, K. (2008). The reliability and validity of the Norwegian version of the Neuropsychiatric Inventory, nursing home version (NPI-NH). International Psychogeriatrics, 20, 375-382. doi: 10.1017/ S1041610207005601 
Selwood, A., Johnston, K., Katona, C., Lyketsos, C. and Livingston, G. (2007). Systematic review of the effect of psychological interventions on family caregivers of people with dementia. Fournal of Affective Disorders, 101, 75-89. doi: 10.1016/j.jad.2006.10.025

Skogseth, R. et al. (2017). Accuracy of clinical diagnosis of dementia with Lewy bodies versus neuropathology. Fournal of Alzheimers Disease, 59, 1139-1152. doi: 10 .3233/JAD-170274

Spijker, A. et al. (2008). Effectiveness of nonpharmacological interventions in delaying the institutionalization of patients with dementia: a meta-analysis. Fournal of the American Geriatrics Society, 56, 1116-1128. doi: 10.1111/j.1532-5415 .2008.01705.x

Svendsboe, E. et al. (2016). Caregiver burden in family carers of people with dementia with Lewy bodies and Alzheimer's disease. International fournal of Geriatric Psychiatry, 31, 1075-1083. doi: 10.1002/gps.4433

Sörensen, S., Duberstein, P., Gill, D. and Pinquart, $M$. (2006). Dementia care: mental health effects, intervention strategies, and clinical implications. The Lancet Neurology, 5, 961-973. doi: 10.1016/S1474-4422(06)70599-3
Toot, S., Swinson, T., Devine, M., Challis, D. and Orrell, M. (2017). Causes of nursing home placement for older people with dementia: a systematic review and meta-analysis. International Psychogeriatrics, 29, 195-208. doi: $10.1017 /$ S1041610216001654

Ulstein, I. (2007). Dementia in the Family. PhD Thesis. Oslo: University of Oslo.

Ulstein, I., Wyller, T. B. and Engedal, K. (2007a). High score on the Relative Stress Scale, a marker of possible psychiatric disorder in family carers of patients with dementia. Int f Geriatr Psychiatry, 22, 195-202. doi: 10 $.1002 /$ gps. 1660

Ulstein, I., Wyller, T. B. and Engedal, K. (2007b). The relative stress scale, a useful instrument to identify various aspects of carer burden in dementia? International Fournal of Geriatric Psychiatry, 22, 61-67. doi: 10.1002 /gps.1654

Wimo, A., Jönsson, L., Bond, J., Prince, M. and Winblad, B. (2013). The worldwide economic impact of dementia 2010. Alzheimer's \& Dementia: The fournal of the Alzheimer's Association, 9, 1-11.e3. doi: 10.1016/j.jalz.2012 .11 .006 